\title{
ENTREPRENEUR
}

Jurnal Bisnis Manajemen Dan Kewirausahaan

Program Studi Manajemen Fakultas Ekonomika dan Bisnis Universitas Majalengka

Published every January and July e-ISSN : (2776-2483), p-ISSN: 2723-1941

Available online http://ejournal.unma.ac.id/index.php/entrepreneur

\section{Pengaruh Kualitas Produk, Harga dan Promosi Terhadap Keputusan Pembelian Jamu Sabdo Palon Di Sukoharjo.}

\author{
Adhita Maharani Dewi ${ }^{1}$, Laurensia Vienanditya Prasdinari ${ }^{2}$ \\ Universitas Kristen Surakarta \\ Email : mawarsharon2012@gmail.com
}

ABSTRACT
This study aims to obtain empirical evidence that partially product quality has a
significant positive effect on consumer purchasing decisions of Sabdo Palon traditional
herbal syrup in Sukoharjo district and obtain empirical evidence that product quality, price
and promotion together have a significant effect on decision to buy traditional herbal syrup
Sabdo Palon in Sukoharjo.
In this research, the sampling technique that the writer use is a non probability
sampling. The method that used in sampling is non-probability sampling, that is the sampling
was not choosen randomly. The type of sampling used in this research is purposive sampling.
The sample used in this research amounted to 100 consumers of traditional herbal syrup
Sabdo Palon in Sukoharjo, data collection in this research using a questionnaire. The data
analysis technique used is validity test, reliability test, classical assumption test and
hypothesis test using SPSS version 16.00 .
The research show the product quality variable has a positive effect on purchasing
decisions with a t value of 4.562 and a significance of 0.000, the price variable does not have
a significant effect on purchasing decisions with a t value of -1.892 and a significance of
0.062, the promotion variable has no significant effect on purchasing decisions. with the $t$
value of -1.07 and a significance of 0.915 . And the results of this study indicate that the
variable product quality, price and promotion together (simultaneously) on purchasing
decisions with a significance value of 0.000. 


\section{ENTREPRENEUR \\ Jurnal Bisnis Manajemen Dan Kewirausahaan \\ Program Studi Manajemen Fakultas Ekonomika dan Bisnis Universitas Majalengka \\ Published every January and July e-ISSN : (2776-2483), p-ISSN: 2723-1941 \\ Available online http://ejournal.unma.ac.id/index.php/entrepreneur}

\section{PENDAHULUAN}

Perkembangan industri jamu di Indonesia dalam beberapa bulan terakhir terus meningkat. Kebutuhan manusia terhadap konsumsi jamu tidak bisa diubah karena semakin lama jamu menjadi kebutuhan pokok manusia. Dikarenakan produk jamu menjadi kebutuhan pokok, produk-produk jamu selalu laris di pasaran. Dikalangan anak muda hingga orang dewasa, produk jamu menjadi minuman cepat saji yang cepat dihidangkan, praktis serta dengan harga yang terjangkau. Jamu selalu dibutuhkan oleh semua orang, apalagi di masa pandemi saat ini, mengkonsumsi jamu sangat dianjurkan untuk menjaga tubuh tetap prima.

Persaingan bisnis dalam penjualan jamu semakin naik dan membuat para pengusaha jamu berlomba untuk membuat dan memasarkan produk jamunya dengan menggunakan strategi yang unik dan menarik untuk memaksimalkan penjualannya, seperti memperindah kemasan jamu. Hambatan yang dialami oleh perusahaan biasanya adalah persaingan antara perusahaan yang sejenis. Konsumen juga mempunyai kekuasaan untuk menentukan produk apa yang dibeli dan kepada siapa ia akan membeli produk tersebut.

Syarat yang harus dipenuhi oleh suatu perusahaan agar dapat sukses dalam persaingan adalah berusaha mencapai tujuan untuk menciptakan dan mempertahankan konsumen.Agar tujuan tersebut dapat tercapai, maka setiap perusahaan harus berupaya menghasilkan dan menyampaikan barang yang diinginkan konsumen dengan harga yang pantas.
Perusahaan jamu dengan berbagai macam merek dan salah satunya Sabdo Palon sudah banyak dipasaran terutama di Kabupaten Sukoharjo. Dikalangan anak muda sampai orang dewasa sudah banyak yang mengenal jamu Sabdo Palon, terbukti dengan banyaknya macam produk yang terjual dipasaran. Inovasi yang diberikan oleh Sabdo Palon adalah mengeluarkan syrup jamu tradisional yang dikemas sangat rapi dan bersih dalam botol kaca yang menarik. Jamu Sabdo Palon memenuhi selera konsumen dengan pilihan jamu seperti syrup jamu tradisional kunir asam, syrup jamu tradisional beras kencur, syrup jamu tradisional gula asam, syrup jamu tradisional jahe jawa, syrup jamu tradisional temulawak. Selain Jamu Sabdo Palon sebagai produsen jamu,terdapat merek lain sebagai pesaing sejenis di bidang jamu yang terkenal dikalangan masyarakat Sukoharjo, yaitu: Jamu Joglo Kresno Wisnu, Jamu Gujati, Jamu Gatutkaca, dan yang lainnya. Akan tetapi, banyak pabrik jamu pesaing dari Sabdo Palon yang belum pernah memproduksi syrup jamu tradisional yang sama dengan Sabdo Palon. Banyak permintaan dari pasar untuk semakin banyak memproduksi dan yang paling laris dipasaran adalah syrup jamu tradisional beras kencur yang terbuat dari kencur, tepung beras, asam jawa, garam, gula merah atau gula pasir dan mempunyai banyak manfaat seperti mengatasi jerawat, melangsingkan tubuh, mengobati batuk, dan mengobati masuk angin. Jamu Sabdo Palon harus mempertahankan mangsa pasarnya dengan mengetahui kebutuhan, keinginan, dan harapan konsumen serta harus paham mengenai bagaiamana konsumen membuat suatu keputusan pembelian terhadap produk yang mereka jual. 


\section{ENTREPRENEUR}

\section{Jurnal Bisnis Manajemen Dan Kewirausahaan}

Program Studi Manajemen Fakultas Ekonomika dan Bisnis Universitas Majalengka Published every January and July e-ISSN : (2776-2483), p-ISSN: 2723-1941

Available online http://ejournal.unma.ac.id/index.php/entrepreneur

\section{KERANGKA TEORITIS DAN HIPOTESIS}

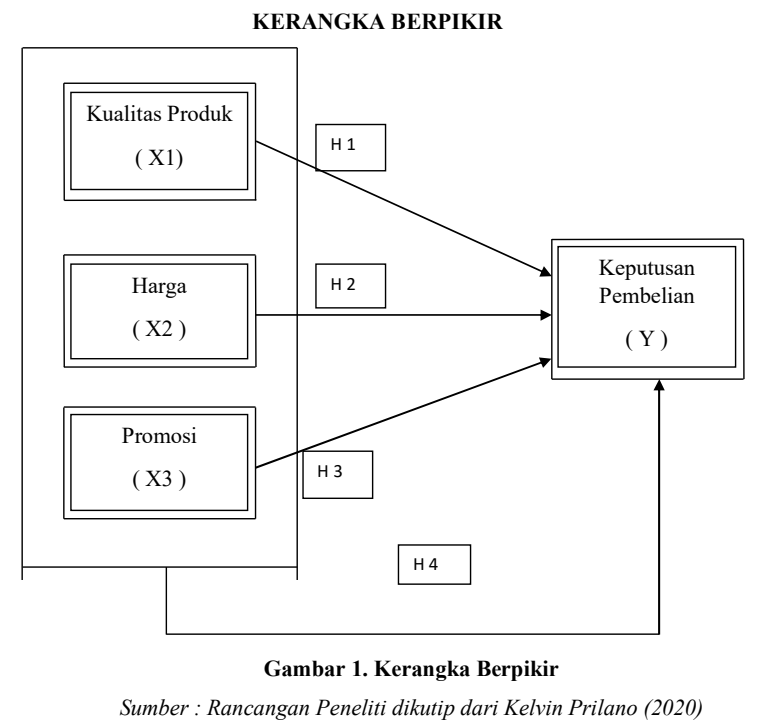

H1: Diduga ada pengaruh kualitas produk terhadap keputusan pembelian jamu Sabdo Palon.

H2: Diduga ada pengaruh harga terhadap keputusan pembelian jamu Sabdo Palon.

H3: Diduga ada pengaruh promosi terhadap keputusan pembelian jamu Sabdo Palon.

H4: Diduga ada pengaruh kualitas produk, harga dan promosi terhadap keputusan pembelian jamu Sabdo Palon.

\section{METODELOGI PENELITIAN}

Pengujian Instrumen Penelitian

\section{Uji Validitas}

Valid berarti instrumen tersebut dapat digunakan untuk mengukur apa yang diinginkan dan dapat menangkap data dari variabel yang diteliti secara tepat.

\section{Uji Reliabilitas}

Penelitian ini menguji reliabilitas instrument dengan menggunakan pengujian reliabilitas internal consistency dengan metode Cronbach's Alpha atau Koefisien Alpha.

\section{Uji Asumsi Klasik \\ Uji Normalitas}

Untuk menentukan normal atau tidak normalnya suatu distribusi data dalam penelitian ini, maka peneliti menggunakan uji normalitas data dengan Klomogorov Smirnov.

\section{Uji Multikolinearitas}

Uji ini bertujuan untuk menguji apakah pada model regresi ditemukan adanya korelasi antar variabel bebas.

\section{Uji Heteroskedastisitas}

Uji heteroskedastisitas dilakukan untuk menguji terjadinya variance residual suatu periode pengamatan dengan periode pengamatan yang lain.

\section{Pengujian Hipotesis}

\section{Analisis Regresi Linear Berganda}

Analisis regresi linear berganda adalah metode statistic umum yang digunakan untuk meneliti hubungan antara sebuah variabel dependent dengan variabel independent. Persamaan regresi untuk menguji hipotesis tersebut adalah sebagai berikut :

$\mathrm{Y}=\beta 1 \mathrm{X} 1+\beta 2 \mathrm{X} 2+\beta 3 \mathrm{X} 3+\mathrm{e}$

Keterangan:

Y $=$ Keputusan Pembelian 


\begin{tabular}{|c|c|}
\hline $\begin{array}{r}\text { ENTRE } \\
\text { Jurnal Bisnis Manaje } \\
\text { Program Studi Manajemen Fakultas E } \\
\text { Published every January and July } \\
\text { Available online http://ejourn }\end{array}$ & $\begin{array}{l}\text { ENEUR } \\
\text { Dan Kewirausahaan } \\
\text { ika dan Bisnis Universitas Majalengka } \\
\text { : (2776-2483), p-ISSN: 2723-1941 } \\
\text { ac.id/index.php/entrepreneur }\end{array}$ \\
\hline 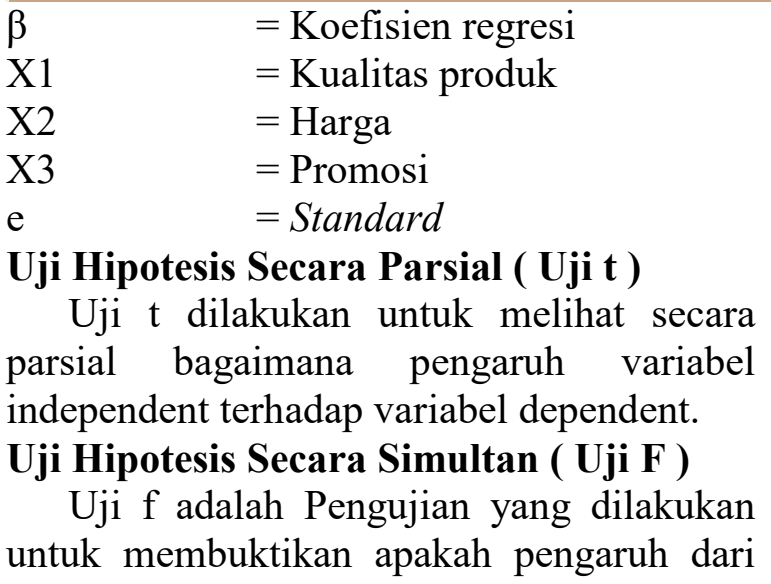 & $\begin{array}{l}\text { variabel independent secara simultan } \\
\text { (menyeluruh) terhadap variabel dependent. } \\
\text { Uji Koefisien Determinasi }\left(\mathbf{R}^{2}\right) \\
\text { Uji koefisien determinasi digunakan } \\
\text { untuk melihat sejauh mana kemampuan } \\
\text { model dapat menjelaskan variabel } \\
\text { dependent. Nilai koefisien determinasi } \\
\text { adalah antara nol (0) dan satu (1). Apabila } \\
\mathrm{R}^{2} \text { mendekati satu (1) berarti variabel- } \\
\text { variabel independent memberikan hampir } \\
\text { semua informasi yang dibutuhkan untuk } \\
\text { memprediksi variasi variabel dependent. }\end{array}$ \\
\hline
\end{tabular}

\section{HASIL DAN PEMBAHASAN}

Tabel 1. Hasil Uji Validitas Variabel Kualitas Produk

\begin{tabular}{cccc}
\hline Variabel & R Hitung & R Tabel & Keterangan \\
\hline $\mathrm{X} 1 \_1$ & 0,749 & 0,196 & Valid \\
\hline $\mathrm{X} 1 \_2$ & 0,772 & 0,196 & Valid \\
\hline $\mathrm{X} 1 \_3$ & 0,836 & 0,196 & Valid \\
\hline $\mathrm{X} 1 \_4$ & 0,821 & 0,196 & Valid \\
\hline $\mathrm{X} 1 \_5$ & 0,816 & 0,196 & Valid \\
\hline
\end{tabular}

Tabel 2. Hasil Uji Validitas Variabel Harga

\begin{tabular}{cccc}
\hline Variabel & r Hitung & R Tabel & Keterangan \\
\hline $\mathrm{X} 2 \_1$ & 0,845 & 0,196 & Valid \\
\hline $\mathrm{X} 2 \_2$ & 0,607 & 0,196 & Valid \\
\hline $\mathrm{X} 2 \_3$ & 0,842 & 0,196 & Valid \\
\hline $\mathrm{X} 2 \_4$ & 0,647 & 0,196 & Valid \\
\hline $\mathrm{X} 2 \_5$ & 0,782 & 0,196 & Valid \\
\hline
\end{tabular}

sumber : data primer yang diolah, 2021

Tabel 3. Hasil Uji Validitas Variabel Promosi

\begin{tabular}{cccc}
\hline Variabel & r Hitung & r Tabel & Keterangan \\
\hline $\mathrm{X} 3 \_1$ & 0,794 & 0,196 & Valid \\
\hline $\mathrm{X} 3 \_2$ & 0,724 & 0,196 & Valid \\
\hline $\mathrm{X} 3 \_3$ & 0,522 & 0,196 & Valid \\
\hline $\mathrm{X} 3 \_4$ & 0,885 & 0,196 & Valid \\
\hline $\mathrm{X} 3 \_5$ & 0,826 & 0,196 & Valid \\
\hline sumber : data primer yang diolah, 2021
\end{tabular}




\section{ENTREPRENEUR}

\section{Jurnal Bisnis Manajemen Dan Kewirausahaan}

Program Studi Manajemen Fakultas Ekonomika dan Bisnis Universitas Majalengka Published every January and July e-ISSN : (2776-2483), p-ISSN: 2723-1941

Available online http://ejournal.unma.ac.id/index.php/entrepreneur

\section{Tabel 4. Hasil Uji Validitas Variabel Keputusan Pembelian}

Variabel r Hitung r Tabel Keterangan

\begin{tabular}{cccc}
\hline Y_1 & 0,638 & 0,196 & Valid \\
\hline Y_2 & 0,641 & 0,196 & Valid \\
\hline Y_3 & 0,694 & 0,196 & Valid \\
\hline Y_4 & 0,643 & 0,196 & Valid \\
\hline Y_5 & 0,616 & 0,196 & Valid
\end{tabular}

sumber : data primer yang diolah, 2021

Tabel 5. Hasil Uji Reliabilitas

\begin{tabular}{cccc}
\hline \multirow{2}{*}{ Variabel } & \multicolumn{3}{c}{ Reliability Statistic } \\
\cline { 2 - 4 } & Cronbach's Alpha & N of Items & Keterangan \\
\hline X1 & 0,858 & 5 & Reliabel \\
\hline X2 & 0,802 & 5 & Reliabel \\
\hline X3 & 0,805 & 5 & Reliabel \\
\hline Y & 0,650 & 5 & Reliabel \\
\hline X1 & 0,858 & 5 & Reliabel \\
\hline
\end{tabular}

sumber : data primer yang diolah, 2021

Tabel 6. Hasil Uji Multikolinearitas

\begin{tabular}{|c|c|c|}
\hline \multirow{2}{*}{ Variabel } & \multicolumn{2}{|c|}{ Collinearity Statistics } \\
\hline & Tolerance & VIF \\
\hline $\mathrm{X} 1$ & 0,978 & 1,023 \\
\hline $\mathrm{X} 2$ & 0,999 & 1,001 \\
\hline $\mathrm{X} 3$ & 0,977 & 1,023 \\
\hline
\end{tabular}

sumber : data primer yang diolah, 2021

Tabel 7. Hasil Uji Heteroskedastisitas

\begin{tabular}{ccc}
\hline Variabel & Nilai Alpha & Signifikansi \\
\hline TOTAL X1 & 0,05 & 0,190 \\
\hline TOTAL X2 & 0,05 & 0,293 \\
\hline TOTAL X3 & 0,05 & 0,137 \\
\hline
\end{tabular}

sumber : data primer yang diolah, 2021

Tabel 8. Hasil Hipotesis Secara Parsial (Uji t)

\begin{tabular}{ccccc}
\hline Variabel & $\mathbf{T}_{\text {hitung }}$ & $\mathbf{T}_{\text {tabel }}$ & sig & Interpretasi \\
\hline TOTAL X1 & 4.562 & 1,660 & .000 & H1 diterima \\
\hline TOTAL X2 & -1.892 & 1,660 & .062 & H2 ditolak \\
\hline TOTAL X3 & -1.07 & 1,660 & .915 & H3 ditolak \\
\hline
\end{tabular}

sumber : data primer yang diolah, 2021 


\section{ENTREPRENEUR \\ Jurnal Bisnis Manajemen Dan Kewirausahaan \\ Program Studi Manajemen Fakultas Ekonomika dan Bisnis Universitas Majalengka \\ Published every January and July e-ISSN : (2776-2483), p-ISSN: 2723-1941 \\ Available online http://ejournal.unma.ac.id/index.php/entrepreneur}

Berdasarkan table 1 menunjukkan bahwa semua pernyataan untuk variabel kualitas produk dinyatakan valid karena $r$ hitung disetiap pernyataan $>\mathrm{r}$ tabel .

Berdasarkan tabel 2 menunjukkan bahwa semua pernyataan untuk variabel kualitas produk dinyatakan valid karena $\mathrm{r}$ hitung disetiap pernyataan $>r$ tabel .

Berdasarkan tabel 3 menunjukkan bahwa semua pernyataan untuk variabel kualitas produk dinyatakan valid karena $r$ hitung disetiap pernyataan $>\mathrm{r}$ tabel .

Berdasarkan tabel 4 menunjukkan bahwa semua pernyataan untuk variabel kualitas produk dinyatakan valid karena $r$ hitung disetiap pernyataan $>r$ tabel .

Berdasarkan tabel 5 menunjukkan bahwa diperoleh nilai Cronbach's Alpha disetiap variabelnya, yaitu variabel Kualitas Produk sebesar 0,858 >0,60, variabel Harga sebesar $0,802>0,60$, variabel Promosi sebesar $0,805>0,60$, variabel Keputusan Pembelian sebesar 0,650>0,60, maka variabel kualitas produk, harga, promosi dan keputusan pembelian dinyatakan reliabel.

Berdasarkan tabel 6 uji multikolinearitas antar variabel kualitas produk (X1), Harga (X2), dan Promosi (X3) tidak terjadi multikolinearitas, dengan kata lain tidak terjadi korelasi. Hal ini dapat dilihat dari VIF $<10,00$ dan nilai tolerance $>0,10$ yaitu : nilai variabel kualitas produk (X1) menunjukkan hasil VIF $1,023<10,00$ dan nilai Itolerance I $0,978>0,10$. Nilai variabel harga (X2) menunjukkan hasil VIF $1,001<$ 10,00 dan nilai tolerance $0,999>0,10$. Nilai variabel promosi menunjukkan hasil VIF $1,023<10,00$ dan nilai tolerance $0,977>$ 0,10 .

Berdasarkan tabel 7 hasil uji heteroskedastisitas pada tabel diatas diketahui bahwa besarnya nilai signifikansi variabel kualitas produk (X1) sebesar 0,190, variabel harga (X2) sebesar 0,293, variabel promosi (X3) sebesar 0,137 yang lebih besar dari 0,05 atau 5\%, sehingga dapat disimpulkan bahwa model regresi bebas dari heteroskedastisitas.

Berdasarkan tabel 8 dapat dilihat bahwa hasil perhitungan koefisien regresi dengan uji t adalah sebagai berikut :

1. Untuk variabel X1 (kualitas produk) diperoleh nilai $\mathrm{t}$ hitung $=4.562$ lebih besar dari t tabel $=1,660(4,562>1,660)$ dengan tingkat siginifikansi 0.000 . Dengan menggunakan batas signifikansi 0,05 , nilai signifikansi tersebut lebih kecil dari taraf 5\% yang berarti Ho ditolak dan $\mathrm{Ha}$ diterima. Dengan demikian, maka hipotesis pertama diterima, itu artinya terdapat pengaruh positif yang signifikan dari kualitas produk (X1) terhadap keputusan pembelian (Y).

2. Untuk variabel $\mathrm{X} 2$ (harga) diperoleh nilai $\mathrm{t}$ hitung $=-1.892$ lebih kecil dari nilai $\mathrm{t}$ tabel $-1,660(-1,892<-1,660)$ dengan tingkat signifikansi 0.062 . Dengan menggunakan batas signifikansi 0,05, nilai signifikansi tersebut lebih besar dari taraf 5\% yang berarti Ho diterima dan $\mathrm{Ha}$ ditolak. Dengan demikian, maka hipotesis kedua ini tidak terbukti, itu artinya tidak ada pengaruh yang signifikan dari harga (X2) terhadap keputusan pembelian (Y).

3. Untuk variabel $\mathrm{X} 3$ (promosi) diperoleh nilai $\mathrm{t}$ hitung $=-1.07$ lebih kecil dari nilai t tabel $-1,660(-1,07<-1,660)$ dengan tingkat signifikansi 0.915 . Dengan menggunakan batas signifikansi 0,05, nilai signifikansi tersebut lebih besar dari taraf 5\% yang berarti Ho diterima dan $\mathrm{Ha}$ ditolak. Dengan demikian, maka hipotesis kedua ini tidak terbukti, itu artinya tidak ada pengaruh yang signifikan dari 


ENTREPRENEUR
Jurnal Bisnis Manajemen Dan Kewirausahaan
Program Studi Manajemen Fakultas Ekonomika dan Bisnis Universitas Majalengka
Published every January and July e-ISSN : (2776-2483), p-ISSN: 2723-1941
Available online http://ejournal.unma.ac.id/index.php/entrepreneur
yang tidak signifikan terhadap keputusan pembelian dengan nilai t.sig sebesar $(0,062)$ lebih besar dari 0,05. Harga tidak berpengaruh positif dan signifikan pada keputusan pembelian. Sehingga dapat disimpulkan bahwa ada tidak ada pengaruh yang tinggi dari harga terhadap keputusan pembelian syrup jamu Sabdo Palon di Kabupaten Sukoharjo.

Variabel promosi mempunyai pengaruh yang tidak signifikan terhadap keputusan pembelian dengan nilai t.sig sebesar $(0,915)$ lebih besar dari 0,05. Promosi tidak berpengaruh positif dan signifikan pada keputusan pembelian. Sehingga dapat disimpulkan bahwa ada tidak ada pengaruh yang tinggi dari promosi terhadap keputusan pembelian syrup jamu Sabdo Palon di Kabupaten Sukoharjo.

Variabel kualitas produk, harga dan promosi secara simultan berpengaruh signifikan terhadap keputusan pembelian. Nilai signifikansi uji F sebesar 0,000<0,05 sehingga dinyatakan $\mathrm{Ha}$ yaitu kualitas produk, harga dan promosi berpengaruh secara simultan sebesar 8,137 terhadap keputusan pembelian.

\section{DAFTAR PUSTAKA}

Astuti, Sri Wulan., 2018. Pengaruh Harga, Kualitas Produk dan Citra Merek Terhadap Keputusan Pembelian Flashdisk Merek Kingston pada Mahasiswa Fakultas Ilmu Komputer dan Teknologi Informasi Universitas Sumatera Utara, diambil Selasa, 4 agustus 2020 pukul 13.40 WIB dari http://repositori.usu.ac.id/handle/1234567 89/6936

Asri, Marwan. 1991. Marketing. Yogyakarta: Unit Penerbit dan Percetakan AMP YKPN.

Apriyani,Maria., (2017) Pengaruh Kualitas Produk Dan Promosi Terhadap Citra Merek Dan Dampaknya Terhadap Keputusan Pembelian Merek Frestea (Survey Pada Mahasiswa/i Program Studi Manajemen FEB UNPAS Bandung), diambil Sabtu, 28 November 2020 pukul 10.51 WIB dari http://repository.unpas.ac.id/31583/
Amin,Muchammad Al. Dkk., (2017)
KLASIFIKASI KELOMPOK UMUR MANUSIA BERDASARKAN ANALISIS DIMENSI 


\section{ENTREPRENEUR}

\section{Jurnal Bisnis Manajemen Dan Kewirausahaan}

Program Studi Manajemen Fakultas Ekonomika dan Bisnis Universitas Majalengka

Published every January and July e-ISSN : (2776-2483), p-ISSN: 2723-1941

Available online http://ejournal.unma.ac.id/index.php/entrepreneur

FRAKTAL BOX COUNTING DARI CITRA WAJAH DENGAN DETEKSI TEPI CANNY, diambil Selasa, 2Maret 2021 pukul 15.03 WIB dari https://www.google.com/url?sa=t\&source $=$ web\&rct=j\&url=https://core.ac.uk/down load/pdf/230755665.pdf\&ved=2ahUKEw ivk6uRk5HvAhUV4nMBHWYxBeEQFj ACegQIDhAC\&usg=AOvVaw2gsazqcZM2SWd8X23hQoU

Devi, Lenggang Kurnia Intan., 2020. Pengaruh Kualitas Produk, Harga Dan Promosi Terhadap Keputusan Pembelian Pada Marketplace Shopee (Studi Kasus pada Mahasiswa di Surabaya), diambil Jumat, 4 september 2020 pukul 15.22 WIB dari http://digilib.uinsby.ac.id/29623/

Fernando, Made Fajar.Dkk., 2018. Pengaruh Kualitas Produk, Harga, Promosi, Dan Distribusi Terhadap Keputusan Pembelian Produk Sanitary Ware Toto Di Kota Denpasar, diambil Kamis, 26 maret 2020 pukul 09.04 WIB dari

https://ojs.unud.ac.id/index.php/Manajemen/ article/view/35419

Hanif, Inne., 2018. Pengaruh Kualitas Produk, Harga, Dan PromosiTerhadap Keputusan Pembelian Teh Pucuk Harum Pada Mahasiswa UN PGRI Kediri (Studi Pada Mahasiswa Manajemen UN PGRI Kediri), diambil Kamis,14 mei 2020 pukul $\quad 15.00 \quad$ WIB dari http://simki.unpkediri.ac.id/detail/13.1.02 .02 .0322

Kotler, Philip dan Keller, Manajemen pemasaran, Edisi 13 Jilid 1,( Jakarta: Erlanggan, 2013)

Lestari, Putri., 2017. Pengaruh Kualitas Produk Dan Harga Terhadap Kepuasan Konsumen Dan Dampaknya Terhadap Kepercayaan Konsumen Teh Botol Sosro
(Studi Pada Mahasiswa Reguler Strata 1 Fakultas Ekonomi dan Bisnis Universitas Pasundan Bandung), diambil Senin,10 Agustus 2020 pukul 15.00 WIB dari http://repository.unpas.ac.id/30183/

Mahendra, Made Mahesa., 2018. Pengaruh Umur, Pendidikan Dan Pendapatan Terhadap Niat Beli Konsumen Pada Produk Kosmetik The Body Shop Di Kota Denpasar, diambil Rabu, 9 september 2020

dari

http://garuda.ristekbrin.go.id/documents/ detail/1369491

Muchlis, Imam., 2015. Pengaruh Stres Kerja Terhadap Kinerja Karyawan Di PT.Batik Danar Hadi Surakarta (Universitas Muhammadiyah Surakarta), diambil Jumat, 6 november 2020 pukul 14.25 WIB dari http://eprints.ums.ac.id/38670/

Priliano, Kelvin. Dkk., 2020. Pengaruh Harga, Keamanan dan Promosi Terhadap Keputusan Pembelian Toko Online Lazada, diambil Minggu, 6 september 2020 pukul 17.03 WIB dari https://ejurnal.seminarid.com/index.php/j be/article/view/56

Prasetiyo, Bundan Rachmad ., 2016. Analisis Pengaruh Harga, Kualitas Produk Dan Promosi Terhadap Pengambilan Keputusan Pembelian Toyota Avanza (Studi Kasus Pada PT. Nasmoco Solo Baru), diambil 25 mei 2020 pukul 19.43 WIB dari https://123dok.com/document/lzge362yanalisis-pengaruh-kualitas-pengambilankeputusan-pengambilan-keputusanpembelian.html\

Personal website tentang keputusan pembelian, diambil senin, 1 Maret 2021 pukul $\quad 12.10 \quad$ WIB. Dari https://www.google.com/search?q=keput usan + pembelian\&oq $=$ keputusan + pembeli 


\section{ENTREPRENEUR}

\section{Jurnal Bisnis Manajemen Dan Kewirausahaan}

Program Studi Manajemen Fakultas Ekonomika dan Bisnis Universitas Majalengka

Published every January and July e-ISSN : (2776-2483), p-ISSN: 2723-1941

Available online http://ejournal.unma.ac.id/index.php/entrepreneur

an\&aqs=chrome..69i57j35i39j0i39516.15

320j1j7\& sourceid $=$ chrome\&ie $=$ UTF-8

Putri,Agatha Rintadiana, 2020. Pengaruh Kualitas Produk,Iklan dan Citra Merek Terhadap Keputusan Pembelian Popeye Fried Chicken (Survei Terhadap Konsumen Popeye Fried Chicken Cabang Kleco). Skripsi Sarjana (tidak dipublikasikan) Fakultas Ekonomi, Universitas Kristen Surakarta.

Pengertian populasi.diambil, Senin 22 maret 2021. Pukul 20.30 WIB. Dari http://www.pengertianku.net/2015/03/pen gertian-populasi-dan-sampel-sertateknik-sampling.html

Ratnasari, Aprillia Dewi. Dkk., (2018) PENGARUH KUALITAS PRODUK, HARGA, LOKASI, DAN KUALITAS LAYANAN TERHADAP KEPUTUSAN PEMBELIAN DI DJAWI LANBISTRO COFFEE AND RESTO SURABAYA, diambil Selasa, 2 Maret 2021 pukul 14.55 WIB dari https://www.google.com/url?sa=t\&source =web\&rct=j\&url=http://staffnew.uny.ac.i d/upload/132318571/pendidikan/Microso $\mathrm{ft} \% 2 \mathrm{BP}$ owerPoint $\% 2 \mathrm{~B}-$ $\% 2 B T A H A P \% 2 B P E R K E M B A N G A N \%$ 2BANAK $\% 2 B U S I A \% 2 B 12-$ 17\%2BTAHUN.pdf\&ved=2ahUKEwj1sd X1kpHvAhXc5nMBHR6dAiMQFjAAeg
QIARAC\&usg=AOvVaw0XDZtKdH3kq j2XMi8NXT7h\&cshid=1614672337056

Santoso, Krestiawan Wibowo., Dkk., 2013. Pengaruh Kualitas Produk, Harga Dan Promosi Terhadap Keputusan Pembelian Permen Tolak Angin Di Semarang (Studi Kasus pada Pengguna Permen Tolak Angin di Kelurahan Tembalang Semarang), diambil Rabu, 25 maret 2020 pukul $\quad 09.43 \quad$ WIB dari https://ejournal3.undip.ac.id/index.php/jia b/article/view/4378

Susanto,Albert Ardyan, 2019. Pengaruh Kualitas Produk,Harga,Promosi Terhadap Keputusan Pembelian Konsumen Martabak Spektakuler Nusukan. Skripsi Sarjana (tidak dipublikasikan) Fakultas Ekonomi, Universitas Kristen Surakarta.

Wahyuni, Naning Tri., 2017. Pengaruh Kualitas Produk, Harga, Dan Promosi Terhadap Keputusan Pembelian Hp Oppo Pada Mahasiswa Fakultas Ekonomi UN PGRI Kediri, diambil, Rabu 25 maret 2020 pukul 10.00 WIB dari

http://simki.unpkediri.ac.id/mahasiswa/fil e_artikel/2017/12.1.02.02.0084.pdf

Widodo,2017. Metodologi Penelitian Populer \& Praktis. Jilid 1. Jakarta : Penerbit PT. Raja Gravindo Persada. 